\title{
Avaliação da suplementação antioxidante na dieta para galos de matrizes pesadas em idade avançada sobre parâmetros reprodutivos
}

\author{
[Evaluation of antioxidant supplementation in diet for aging broiler breeder roosters on \\ reproductive parameters]

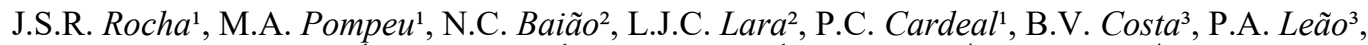 \\ A.C. Leite ${ }^{1}$, L.R. Vargas $^{1}$, C.A. Rezende ${ }^{1}$, B. Wernick ${ }^{4}$, J.H.A. Ruiz ${ }^{4}$ \\ ${ }^{1}$ Aluno de pós-graduação - Escola de Veterinária - UFMG - Belo Horizonte, MG \\ ${ }^{2}$ Escola de Veterinária - Universidade Federal de Minas Gerais - EV-UFMG - Belo Horizonte, MG \\ ${ }^{3}$ Pontifícia Universidade Católica de Minas Gerais - PUC-Minas - Belo Horizonte, MG \\ ${ }^{4}$ Autônomo - São Paulo, SP
}

\begin{abstract}
RESUMO
Objetivou-se avaliar os efeitos de antioxidantes suplementados às dietas de galos de matrizes pesadas em idade avançada sobre as características reprodutivas. Foram utilizados galos da linhagem Cobb com 47 semanas de idade. Estes foram distribuídos em quatros tratamentos, de acordo com a adição de antioxidante à dieta, sendo: $\mathrm{A}=$ grupo controle (sem suplementação antioxidante); $\mathrm{B}=$ suplementação de 9ppm de citranaxantina; $\mathrm{C}=$ suplementação de $6 \mathrm{ppm}$ de cantaxantina e $\mathrm{D}=150 \mathrm{ppm}$ de vitamina $\mathrm{E}$. Foram avaliadas as características seminais, tais como volume, vigor, motilidade e concentração, a composição de ácidos graxos do sêmen (saturados, insaturados, monoinsaturados, poli-insaturados, ômega 3, ômega 6 e ômega 9) e a correlação entre o peso dos testículos e o peso dos galos. Não foram observados efeitos das substâncias antioxidantes testadas sobre os parâmetros reprodutivos avaliados. Os antioxidantes avaliados não influenciam as respostas reprodutivas de machos reprodutores de matrizes pesadas em idade avançada.
\end{abstract}

Palavras-chave: avicultura, cantaxantina, reprodução, sêmen, vitamina E

\begin{abstract}
This study aimed to evaluate the effect of antioxidant supplementation in diets of aging broiler breeder roosters on reproductive characteristics. Cobb roosters were divided into four groups, according to antioxidant addition, where: $A=$ control group (without antioxidant supplementation); $B=9 p p m$ of citranaxanthin; $C=6 \mathrm{ppm}$ of canthaxanthin, and D $=150 \mathrm{ppm}$ of vitamin E. Seminal characteristics (volume, force, motility and concentration), semen fatty acid composition (saturated, unsaturated, monounsaturated, polyunsaturated, $\omega 3, \omega 6$ and $\omega 9)$ ), and the correlation between testis weight with rooster weight were evaluated. No effects of the antioxidants tested were observed. The antioxidants do not influence the reproductive responses of aging male broiler breeder.
\end{abstract}

Keywords: antioxidant, broiler breeder, male, semen

\section{INTRODUÇÃO}

A redução da fertilidade com o aumento da idade das aves, em lotes de matrizes pesadas, é de responsabilidade tanto dos machos quanto das fêmeas. No entanto, esses problemas estão mais relacionados aos machos, visto que, utilizando-se a inseminação artificial, a fertilidade de um lote permanece mais alta por um maior período de tempo (Brillard e McDaniel, 1986). A queda da fertilidade tem início às 40 semanas de idade das aves, sendo mais pronunciada após 50 semanas (Hocking, 1989; Lake, 1989). De acordo com Makker et al. (2009), o plasma seminal e os

Recebido em 9 de maio de 2014

Aceito em 3 de março de 2016

E-mail: juliasrr@yahoo.com.br 
espermatozoides contêm enzimas e vitaminas antioxidantes que protegem a membrana espermática, rica em ácidos graxos poliinsaturados (PUFA), da peroxidação. Porém, essa atividade enzimática antioxidante dos espermatozoides se torna menor com o passar da idade dos galos. Dessa forma, a ingestão de substâncias com propriedades antioxidantes, tais como a citranaxantina, a cantaxantina e a vitamina E (alfatocoferol), auxilia os mecanismos de defesa enzimáticos no controle dos danos causados nas células pelos radicais livres.

Apesar de os carotenoides serem conhecidos como precursores de vitamina A, esses possuem importante papel antioxidante, pois removem radicais livres, absorvem e dissipam o excesso de energia destes e reciclam a vitamina $\mathrm{E}$ (Böhm et al., 1997). Rocha et al. (2013) adicionaram cantaxantina à dieta de matrizes pesadas e foi observado o efeito significativo desse carotenoide sobre os índices de fertilidade e eclosão dos ovos de aves em idade avançada. Nesta pesquisa, a melhora pode ser atribuída ao efeito do antioxidante na proteção dos tecidos embrionários durante a incubação, na preservação dos nutrientes da gema durante o armazenamento dos ovos e no auxílio aos mecanismos antioxidantes do sêmen e do oviduto para reduzir o estresse oxidativo dos espermatozoides. Já os antioxidantes primários, como é o caso da vitamina $\mathrm{E}$, atuam bloqueando a ação dos radicais livres, convertendo-os em produtos estáveis por meio da doação de hidrogênio ou elétrons, além de reagirem com os radicais lipídicos, formando o complexo antioxidante-lipídio (Araújo, 2006).

Com base nos aspectos apresentados, foi conduzido um experimento com o objetivo de avaliar os efeitos da suplementação de antioxidantes às dietas de galos de matrizes pesadas em idade avançada sobre as características reprodutivas.

\section{MATERIAL E MÉTODOS}

O experimento foi realizado na Fazenda Experimental Professor Hélio Barbosa da Escola de Veterinária da Universidade Federal de Minas Gerais (UFMG), localizada no município de Igarapé/MG.
Foram utilizados 48 galos da linhagem Cobb com 45 semanas de idade, oriundos de um matrizeiro comercial. As aves foram alojadas em galpão convencional dividido em boxes, sendo uma ave por boxe. De 45 a 47 semanas de idade, foi realizado o período de adaptação das aves. A partir de 47 semanas de idade, as aves foram distribuídas em quatro tratamentos, sendo cada ave considerada uma repetição.

Os tratamentos foram definidos de acordo com os antioxidantes adicionados às dietas experimentais, sendo: $\mathrm{A}=$ grupo controle (sem suplementação antioxidante); B = suplementação de 9ppm de citranaxantina; $\mathrm{C}=$ suplementação de 6 ppm de cantaxantina e $\mathrm{D}=150 \mathrm{ppm}$ de vitamina E. Os galos receberam diariamente $140 \mathrm{~g}$ de ração, sempre no mesmo período do dia (às oito horas da manhã).

Para a formulação das dietas, foram considerados os valores dos ingredientes estabelecidos por Rostagno et al. (2011). A composição das rações e seus níveis nutricionais calculados encontramse na Tab. 1.

dos galos às $47,49,51,53$ e 55 semanas de idade, características seminais de 51 a 55 semanas de idade, composição dos ácidos graxos do sêmen e peso dos testículos.

Para a avaliação das características seminais, o sêmen dos galos foi coletado mediante massagem dorsoabdominal, e foram registrados o volume, a motilidade progressiva (0 a 100\%), o vigor (escore de 0 a 5 - sendo zero para a ausência de vigor e cinco para a atividade máxima dessa característica) e a concentração espermática seminal, determinada por meio de microscopia em contraste de fase, pela contagem dos espermatozoides com o uso de hemocitrômetro (câmara de Neubauer), de acordo com a técnica descrita por Brillard e McDaniel (1985). Para essa avaliação, uma alíquota de $10 \mu \mathrm{L}$ de sêmen foi adicionada a $4 \mathrm{~mL}$ de solução formol salina tamponada (PBS-10\%, $\mathrm{pH}$ 7,2) e acondicionada em recipiente identificado e mantido a $4^{\circ} \mathrm{C}$ até o momento da análise. 
Avaliação da suplementação...

Tabela 1. Composição percentual e níveis nutricionais calculados das rações experimentais

\begin{tabular}{lc}
\hline \multicolumn{1}{c}{ Ingredientes } & Ração basal \\
\hline Milho & 63,0 \\
Farelo de soja (45\% PB) & 12,4 \\
Farinha de carne e osso (46\% PB) & 3,25 \\
Farelo de trigo & 13,75 \\
Calcário & 7,00 \\
Sal comum & 0,325 \\
Suplemento vitamínico/mineral* & 0,15 \\
DL-metionina & 0,0625 \\
L-lisina HCL & 0,0125 \\
Cloreto de colina 60\% & 0,05 \\
\hline TOTAL & 100,0 \\
\hline & \\
\hline Energia (kcal/kg) & 2.474 \\
Proteína bruta (\%) & 14,32 \\
Cálcio (\%) & 3,15 \\
Fósforo disponível (\%) & 0,301 \\
Lisina digestível (\%) & 0,572 \\
Met + Cis digestível (\%) & 0,460 \\
Metionina digestível (\%) & 0,261 \\
Treonina digestível (\%) & 0,448 \\
Sódio (\%) & 0,172 \\
Vitamina E total (ppm) & 40,00 \\
\hline Suplemo & \\
\hline
\end{tabular}

*Suplemento matriz pesada (produção): vitamina A 8.000.000UI; vitamina D 2.500.000UI; vitamina E 40.000mg; vitamina K3 2.200mg; vitamina B1 $2.500 \mathrm{mg}$; vitamina B2 $8.000 \mathrm{mg}$; vitamina B6 $3.500 \mathrm{mg}$; vitamina B12 $15.000 \mathrm{mcg}$; ácido fólico $1.200 \mathrm{mg}$; ácido pantotênico $13.000 \mathrm{mg}$; niacina $35.000 \mathrm{mg}$; biotina $150.000 \mathrm{mcg}$; selênio $300 \mathrm{mg}$; manganês $90 \mathrm{mg}$; zinco $80 \mathrm{mg}$; ferro $30 \mathrm{mg}$; cobre $10 \mathrm{mg}$; iodo $2 \mathrm{mg}$.

**Tratamento A (controle): não foi adicionado nenhum antioxidante; tratamento B: foram adicionados $90 \mathrm{ppm}$ de citranaxantina (concentração de $10 \%$ ); tratamento $\mathrm{C}$ : foram adicionados $60 \mathrm{ppm}$ de cantaxantina (concentração de $10 \%$ ) e tratamento D: foram adicionados $220 \mathrm{mg} / \mathrm{kg}$ de vitamina $\mathrm{E}$ (acetato de dl-alfatocoferil $50 \%$ ).

As seguintes variáveis foram analisadas: peso

A composição dos ácidos graxos do sêmen foi avaliada por meio de cromatografia líquida de alta eficiência. Para a obtenção da quantidade satisfatória de sêmen, as amostras foram constituídas por um pool de sêmen de quatro galos do mesmo tratamento, as quais foram congeladas em nitrogênio líquido e armazenadas até o momento da análise, quando cada pool foi considerado uma repetição.

Ao final do período experimental, os galos foram abatidos. Os testículos foram coletados, e seus pesos registrados. Cada galo foi considerado uma repetição, sendo 12 repetições por tratamento.

O delineamento experimental foi inteiramente ao acaso, sendo quatro tratamentos e 12 repetições para o peso dos galos, as características seminais e o peso dos testículos, e quatro repetições por tratamento para a composição dos ácidos graxos do sêmen. Os dados foram submetidos à análise de variância, e as médias foram comparadas pelo teste F. As medianas das características seminais foram comparadas pelo teste de Kruskal-Wallis (Sampaio, 2007).

A metodologia utilizada foi aprovada pelo Comitê de Ética em Experimentação Animal da UFMG, sob protocolo 144/2009.

\section{RESULTADOS E DISCUSSÃO}

Na Tab. 2, estão apresentados os resultados de peso corporal dos galos de acordo com a suplementação antioxidante. 
Tabela 2. Peso corporal $(\mathrm{kg})$ de galos de matrizes pesadas de acordo com a suplementação antioxidante

\begin{tabular}{lccccc}
\hline \multicolumn{1}{c}{ Tratamentos } & 47 semanas & 49 semanas & 51 semanas & 53 semanas & 55 semanas \\
\hline Controle & 4,948 & 4,957 & 5,051 & 5,175 & 5,177 \\
Citranaxantina & 5,014 & 5,033 & 5,090 & 5,212 & 5,175 \\
Cantaxantina & 5,058 & 5,056 & 5,115 & 5,252 & 5,223 \\
Vitamina E & 5,130 & 5,102 & 5,167 & 5,281 & 5,255 \\
\hline \multicolumn{1}{c}{ CV (\%) } & 7,3 & 7,1 & 6,5 & 5,9 & 5,6 \\
\hline
\end{tabular}

Médias não seguidas por letras na coluna são semelhantes entre si pelo teste $\mathrm{F}(\mathrm{P}>0,05)$.

Conforme observado na Tab. 2, os pesos dos galos foram semelhantes entre os tratamentos em todas as idades $(\mathrm{P}>0,05)$. Isso era esperado, visto que as aves recebiam a mesma dieta, diferindo apenas a adição dos antioxidantes.

Os pesos das aves foram avaliados para garantir que os galos de todos os tratamentos apresentassem peso médio semelhante, uma vez que este é um fator que interfere na fertilidade.
De acordo com Duncan et al. (1990), Robinson et al. (1993) e Hocking e Bernard (1997b), o excesso de peso, principalmente dos machos, leva a uma queda da fertilidade.

$\mathrm{Na}$ Tab. 3, estão apresentados os resultados das características seminais dos sêmens dos galos, de 51 a 55 semanas de idade, de acordo com a suplementação de antioxidantes à dieta.

Tabela 3. Volume, vigor, motilidade progressiva e concentração espermática do sêmen de galos de acordo com a suplementação antioxidante

\begin{tabular}{lcccc}
\multicolumn{1}{c}{ Tratamentos } & Volume $(\mathrm{mL})$ & Vigor* (escore) $^{*}$ & Motilidade* $(\%)$ & Concentração (sptz/mL) \\
\hline Controle & 0,18 & 4,00 & 55 & $10,7 \times 10^{8}$ \\
Citranaxantina & 0,22 & 3,50 & 50 & $5,5 \times 10^{8}$ \\
Cantaxantina & 0,26 & 4,50 & 75 & $7,4 \times 10^{8}$ \\
Vitamina E & 0,22 & 4,25 & 75 & $5,8 \times 10^{8}$ \\
\hline \multicolumn{1}{c}{ CV (\%) } & 46,8 & - & - & 77,9 \\
\hline
\end{tabular}

Médias não seguidas de letras na coluna são semelhantes entre si pelo teste $\mathrm{F}(\mathrm{P}>0,05)$.

*Medianas não seguidas de letras na coluna são semelhantes entre si pelo teste de Kruskal-Wallis $(\mathrm{P}>0,05)$.

Não foi observado efeito significativo sobre o volume de sêmen, o vigor, a motilidade progressiva e a concentração espermática $(\mathrm{P}>0,05)$, demonstrando que os antioxidantes dietéticos avaliados não exerceram efeito sobre essas características. Esses resultados estão de acordo com Rodenas et al. (2005), os quais não observaram efeito da utilização de antioxidante (vitamina E) na dieta sobre as características seminais de galos de matrizes leves.

Em aves, a ausência de vesículas seminais e de glândula prostática resulta em reduzido volume seminal (variando entre 0,05 a $0,30 \mathrm{~mL}$ ), o qual é composto basicamente de frutose, fosfatidilcolina e alguns eletrólitos (Parkhurst e Mountney, 1988).

A concentração do sêmen coletado artificialmente é muito variável, pois existe dificuldade no controle de fatores influenciadores, como os líquidos dos sistemas digestivo e urinário, que podem se misturar ao sêmen no aparelho fálico (Burke, 1996).

$\mathrm{Na}$ Tab. 4, está apresentada a composição em ácidos graxos do sêmen dos galos em função dos tratamentos.

Não foi observada diferença entre os tratamentos quanto à composição em ácidos graxos do sêmen $(\mathrm{P}>0,05)$. Sabendo-se que aproximadamente $70 \%$ dos ácidos graxos dos espermatozoides são insaturados e que a maioria destes é poliinsaturada, esperava-se que a suplementação dos antioxidantes na dieta apresentasse efeito protetor sobre a peroxidação deles em relação ao grupo controle. 
Tabela 4. Composição percentual em ácidos graxos do sêmen de galos (saturados, insaturados, monoinstaurados, poli-insaturados, ômega 3, ômega 6 e ômega 9) de acordo com a suplementação antioxidante

\begin{tabular}{lccccccc}
\multicolumn{1}{c}{ Tratamentos } & Sat & Insat & Mono & Poli & $\omega 3$ & $\omega 6$ & $\omega 9$ \\
\hline Controle & 32,0 & 68,0 & 26,0 & 42,0 & 12,7 & 28,5 & 22,9 \\
Citranaxantina & 34,6 & 65,4 & 27,0 & 38,4 & 10,9 & 26,8 & 24,1 \\
Cantaxantina & 33,0 & 67,0 & 26,5 & 40,5 & 11,9 & 27,7 & 23,0 \\
Vitamina E & 32,1 & 67,9 & 26,9 & 41,0 & 10,5 & 29,9 & 23,2 \\
\hline \multicolumn{1}{c}{ CV (\%) } & 11,5 & 5,7 & 11,2 & 11,6 & 25,1 & 17,5 & 17,5 \\
\hline
\end{tabular}

Médias não seguidas por letras na coluna são semelhantes entre si pelo teste $\mathrm{F}(\mathrm{P}>0,05)$.

$\mathrm{Na}$ Tab. 5, estão apresentados os resultados do peso dos testículos esquerdo e direito e a correlação entre esses pesos com o peso corporal dos galos.

Não foi observado efeito dos tratamentos sobre o peso dos testículos, e o peso dos galos não está correlacionado ao peso dos testículos $(\mathrm{P}>0,05)$. No entanto, Fontana et al. (1990) e Hocking e Bernard (1997a) observaram correlação positiva significativa entre o peso dos testículos e o peso corporal de galos.

Tabela 5. Peso dos testículos esquerdo e direito e correlação de Pearson (r) com os pesos dos galos

\begin{tabular}{lccc}
\multicolumn{1}{c}{ Tratamentos } & Testículo esquerdo $(\mathrm{g})$ & Testículo direito $(\mathrm{g})$ & Correlação $(\mathrm{r})$ \\
\hline Controle & 5,8 & 5,6 & $\mathrm{~ns}$ \\
Citranaxantina & 7,8 & 6,7 & $\mathrm{~ns}$ \\
Cantaxantina & 6,1 & 5,6 & $\mathrm{~ns}$ \\
Vitamina E & 8,2 & 7,4 & $\mathrm{~ns}$ \\
\hline \multicolumn{1}{c}{ CV $(\%)$} & 50,2 & 52,8 & - \\
\hline
\end{tabular}

Médias não seguidas por letras na coluna são semelhantes entre si pelo teste $\mathrm{F}(\mathrm{P}>0,05)$.

\section{CONCLUSÕES}

De acordo com as condições experimentais, conclui-se que os antioxidantes testados não são capazes de influenciar os parâmetros reprodutivos avaliados de machos reprodutores de matrizes pesadas em idade avançada.

\section{AGRADECIMENTOS}

À Fundação de Amparo à Pesquisa do Estado de Minas Gerais (Fapemig), pela concessão do financiamento ao projeto APQ-02072/11, que deu origem ao presente artigo científico; à empresa BASF S.A., parceira nesta pesquisa.

\section{REFERÊNCIAS}

ARAÚJO, J.M.A. Química de alimentos: teoria e prática. 3.ed. Viçosa: UFV, 2006. 478p.

BÖHM, F.; EDGE, R.; LAND, E.J. et al. Carotenoids enhance vitamin $\mathrm{E}$ antioxidant efficiency. J. Am. Chem. Soc., v.119, p.621-622, 1997.
BRILLARD, J.P.; McDANIEL, G.R. Influence of spermatozoa numbers and insemination frequency on fertility in dwarf broiler breeder hens. Poult. Sci., v.65, p.2330-2334, 1986.

BRILLARD, J.P.; McDANIEL， G.R. The reliability and efficiency of various methods for estimating spermatozoa concentration. Poult. Sci., v.64, p.155-158, 1985.

BURKE, W.H. Reprodução das aves. In: DUKES, H. H. Dukes: fisiologia dos animais domésticos. 11.ed. Rio de Janeiro: Guananbara, 1996. p.660-680.

DUCAN, I.J.H.; HOCKING, P.M.; SEAWRIGTH, E. Sexual behaviour and fertility in broiler breeder domestics fowl. Appl. Anim. Behav. Sci., v.26, p.201-213, 1990.

FONTANA, E.A.; WEAVER JR., W.D.; VAN KREY, H.P. Effect of various feeding regimens on reproduction in broiler-breeder males. Poult. Sci., v.69, p.209-216, 1990. 
HOCKING, P.M. Effect of dietary crude protein concentration on semen yield and quality in male broiler breeder fowls. Br. Poult. Sci., v.30, p.935-945, 1989.

HOCKING, P.M.; BERNARD, R. Effects of dietary crude protein content and food intake on the production of semen in two lines of broiler breeder males. Br. Poult. Sci., v.38, p.199-202, $1997 \mathrm{a}$.

HOCKING, P.M.; BERNARD, R. Effects of male body weight, strain and dietary protein content on fertility and musculo-skeletal disease in naturally mated broiler breeder males. $\mathrm{Br}$. Poult. Sci., v.38, p.29-37, 1997b.

LAKE, P.E. Recent progress in poultry reproduction. World's Poult. Sci. J., v.45, p.5359, 1989.

MAKKER, K.; AGARWAL, A.; SHARMA, R. Oxidative stress \& male infertility. Indian $J$. Med. Res., v.129, p.357-367, 2009.

PARKHURST, C.R.; MOUNTNEY, G.J Poultry meat and egg production. New York: Avi Book, 1988. 294p.
ROBINSON, F.E.; WILSON, J.L.; YU, M.W. et al. The relationship between body weight and reproductive efficiency in mesttype chickens. Poult. Sci., v.72, p.912-922, 1993.

ROCHA, J.S.R.; BARBOSA, V.M.; LARA, L.J.C. et al. Efeito do armazenamento e da cantaxantina dietética sobre sobre a qualidade do ovo fértil e do desenvolvimento embrionário. Arq. Bras. Med. Vet. Zootec., v.65, p.792-800, 2013.

RODENAS, C.E.O.; MURGAS, L.D.S.; MACIEL, M.P. et al. Características seminais de galos alimentados com rações suplementadas com diferentes óleos e níveis de vitamina $\mathrm{E}$. Ciênc. Agrotec., v.29, p.160-167, 2005.

ROSTAGNO, H.S.; ALBINO, L.F.T.; DONZELE, J.L. et al. Tabelas brasileiras para aves e suínos: composição de alimentos $\mathrm{e}$ exigências nutricionais. 3.ed. Viçosa: Universidade Federal de Viçosa, 2011. 252p.

SAMPAIO, I.B.M. Estatística aplicada à experimentação animal. 3.ed. Belo Horizonte: FEPMVZ, 2007. 265p. 